\title{
Qualidade do carvão vegetal obtido a partir da espécie Cecropia glaziovii Sneth. produzido na agricultura familiar em Santa Catarina
}

\author{
Quality of the charcoal obtained from the Cecropia glaziovii Sneth. species produced in the family- \\ based agriculture in Santa Catarina
}

\author{
Adriel Furtado de Carvalho ${ }^{1}$, Martha Andreia Brand ${ }^{2 \star}$, Pedro Higuchi ${ }^{2}$, Ana Carolina da Silva ${ }^{2}$ \\ ${ }^{1}$ Universidade para o Desenvolvimento do Alto Vale do Itajaí, Rio do Sul, SC, Brasil. \\ ${ }^{2}$ Universidade do Estado de Santa Catarina, Lages, SC, Brasil. *Autor para correspondência: martha.brand@udesc.br.
}

Submissão: 14/03/2017 / Aceite: 10/12/2019

\begin{abstract}
RESUMO
O objetivo deste trabalho foi avaliar a qualidade do carvão vegetal da espécie Cecropia glaziovii, produzido em pequenas propriedades rurais, no município de Biguaçu, estado de Santa Catarina, e em laboratório e comparar suas propriedades ao carvão vegetal de outras espécies. Foram analisadas amostras de carvão de três fontes: amostras de carvão de Cecropia glaziovii coletadas dos fornos de alvenaria (1), amostras de carvão produzido nestes mesmos fornos, porém a partir de várias espécies diferentes (2) e amostras obtidas a partir da carbonização em laboratório da madeira de três árvores de Cecropia glaziovii coletada nas mesmas propriedades rurais (3). Determinou-se o poder calorífico superior, porcentagem de voláteis e carbono fixo e teor de cinzas. Analisando as amostras de carvão vegetal, as médias para análise energética mostraram que o carvão vegetal da amostra 2 apresentou melhores características comparadas às amostras 1 e 3 . A amostra 2 apresentou maior poder calorífico superior (PCS - $7.281 \mathrm{Kcal} / \mathrm{Kg}$ a $7.336 \mathrm{Kcal} / \mathrm{Kg}$ ), menor teor de voláteis $(\mathrm{TV}-26,26 \%$ ), menor teor de cinzas (TC - 2,05 a 2,46\%) e maior teor de carbono fixo $(66,02 \%)$. As médias das propriedades da amostra 3 também foram comparadas com outras espécies de importância comercial para produção de carvão. O poder calorífico superior $(6.573 \mathrm{Kcal} / \mathrm{Kg})$ e porcentagem de carbono fixo $(61,32 \%)$ foram respectivamente inferiores quando comparados ao carvão de outras espécies: Mimosa scabrella (7.201,28 Kcal/Kg; $85,40 \%)$, Eucalyptus bentamii $(8.777 \mathrm{Kcal} / \mathrm{Kg} ; 81,85 \%)$ e Eucalyptus grandis $(7.632$ $\mathrm{Kcal} / \mathrm{Kg} ; 75-80 \%)$. A porcentagem de voláteis $(35,00 \%)$ e teor de cinzas $(3,68 \%)$ foram superiores respectivamente aos das outras espécies: Mimosa scabrella (12,70\%; 1,90\%), Eucalyptus bentamii (17, $17 \% ; 0,96 \%)$ e Eucalyptus grandis $(20-25 \% ; 1,70 \%)$. Os resultados indicam que a qualidade do carvão Cecropia glaziovii é inferior em comparação com outras espécies, porém se aceita o uso, devido à abundância da espécie nesta região.
\end{abstract}

PALAVRAS-CHAVE: propriedades energéticas, carbonização, carvão domiciliar.

\section{ABSTRACT}

The objective of this work was to assess the quality of the charcoal of the species Cecropia glaziovii, produced in small rural properties, in the municipality of Biguaçu, in the state of Santa Catarina, and in the laboratory and to compare its properties with charcoal from other species. We analyzed charcoal samples from three sources: charcoal samples collected from Cecropia glaziovii kilns Biguaçu, SC (1), charcoal samples produced in these same kilns, but from several different species (2) and samples obtained from the laboratory carbonization of woods from three Cecropia glaziovii trees collected in the same rural properties (3). It was determined the gross calorific value, percentage of volatile, percentage of ash, and fixed carbon. Analyzing the samples of charcoal, the averages for the energy analysis showed that the charcoal from sample 2 presents better characteristics compared to the samples 1 and 3 . Sample 2 had a gross calorific value (GCV - 7,281 Kcal/Kg to 7,336 Kcal/Kg), lowest volatiles content (TV - 26.26\%), lower ash content (TC -2.05 to $2.46 \%$ ) and higher fixed carbon content (66.02\%). The average of the properties of Sample 3 was also compared to other species of commercial importance to produce charcoal. The gross calorific value $(6,573 \mathrm{Kcal} / \mathrm{Kg})$ and percentage of fixed carbon $(61.32 \%)$ were respectively lower when compared to other carbon species: Mimosa scabrella $(7201.28 \mathrm{Kcal} / \mathrm{Kg} ; 85.40 \%)$, Eucalyptus bentamii $(8,777 \mathrm{Kcal} / \mathrm{Kg} ; 81.85 \%)$, and Eucalyptus grandis $(7632 \mathrm{Kcal} / \mathrm{Kg} ; 75-80 \%)$. The percentage of volatile $(35.00 \%)$ and ash $(3.68 \%)$ were respectively higher than those from other species: Mimosa scabrella (12.70\%; 1.90\%), Eucalyptus bentamii (17.17\%; 0.96\%) and Eucalyptus grandis $(20-25 \%$; 
$1.70 \%$ ). The results indicate that the quality of the Cecropia glaziovii charcoal is lower when comparing to other species. However, its production is recommended due to the abundance of the species in this region.

KEYWORDS: energy properties, carbonization, grilling charcoal.

\section{INTRODUÇÃO}

As propriedades rurais podem ser divididas em minifúndios, pequenas, médias e grandes propriedades em função do tamanho de suas áreas, conforme classificação definida pela Lei 8.629 , de 25 de fevereiro de 1993, que leva em conta o módulo fiscal, e que varia de acordo com cada município (INCRA 2019). Com base nesta classificação, compilando os dados do censo de 2016, pode-se concluir que os minifúndios e pequenas propriedades rurais, que praticam agricultura familiar correspondem a $75,67 \%$ dos estabelecimentos agropecuários no estado de Santa Catarina (IBGE 2019). Isso mostra a relevância da atividade no estado.

Em algumas propriedades de Biguaçu, litoral de Santa Catarina, a agricultura familiar utiliza um sistema conhecido como "roça de toco ou coivara". Neste sistema, a floresta nativa é derrubada e posteriormente queimada, transformando a área em cultivo de mandioca, milho, feijão, batata doce, etc. Por explorar os recursos de fertilidade do solo, em um período aproximado de seis a oito anos, estas áreas são deixadas em "descanso" por 15 a 20 anos, havendo necessidade de encontrar outra área para plantio (SIMINSKI \& FANTINI 2007). A madeira retirada destas áreas após a queima é transformada em carvão nos fornos de alvenaria.

Neste contexto, a produção de carvão vegetal, surge como uma alternativa rentável para estes agricultores, de grande importância econômica na região de Biguaçu, apesar de ser desconhecido da população em geral (ULLER-GÓMEZ \& GARTNER 2008, STEENBOCK 2009, LINDEMANN 2010). Estudos revelam que $30 \%$ das famílias inseridas nas áreas de estudo, em Biguaçu, tem a produção de carvão vegetal como principal fonte de renda. Apesar destes dados serem expressivos, o IBGE desconsidera a atividade carvoeira na região (ULLER-GÓMEZ \& GARTNER 2008).

A variabilidade de espécies componentes do carvão vegetal é grande e equivalente a da vegetação utilizada para tal fim. Como normalmente trata-se de áreas com vegetação secundária, existe a predominância de espécies pioneiras na composição do carvão vegetal. BRAND et al. (2013) afirmaram que na região de estudo, os agricultores destacaram que a Miconia cinnamomifolia (De Candolle) Naudin), Hyeronima alchorneoides Allemão, Mimosa scabrella Bentham, Cecropia glaziovii Sneth. e Pera glabrata (Schott) Poepp. ex Baill são as espécies mais importantes e representativas na composição do carvão vegetal.

Portanto, a Cecropia glaziovii (embaúba), aparece entre as madeiras moles mais citadas pelos agricultores para a produção de carvão vegetal. Além disso, se destaca dentro das principais espécies encontradas no componente arbóreo/arbustivo que abrange 30 - $500 \mathrm{~m}$ de altitude (LINGNER et al. 2013).

A Cecropia glaziovii, conhecida como embaúba-vermelha, tem hábito arbóreo podendo atingir 8-16 m de altura, onde formigas agressivas habitam no interior de seu tronco (20-30 cm de diâmetro). As folhas são simples, com lâminas lobadas, discolores e peltadas, principal alimento para o bicho preguiça. As infrutescências cilíndricas produzem frutos carnosos e adocicados, apreciados por aves a outros animais (LORENZI 2002). A madeira é pouco resistente e durável, de densidade igual a $0,41 \mathrm{~g} / \mathrm{cm}^{3}$, sendo utilizados na fabricação de pólvora, brinquedos, caixotes, saltos de calçados, compensados, forros, aeromodelos, palitos de fósforos, jangadas e flutuadores (LORENZI 2002).

Desta forma, trabalhos que caracterizem e avaliem a qualidade do carvão produzido a partir das principais espécies utilizadas para a produção de carvão vegetal na agricultura familiar são de suma importância, isso porque, determinarão a qualidade do carvão produzido a partir das várias espécies utilizadas pelos agricultores. Os resultados destas pesquisas permitirão a classificação das espécies antes do processo de carbonização, visando a homogeneização do produto. Os agricultores terão acesso as informações de qualidade energética do carvão, e poderão usá-las para melhorar o preço de venda do produto no mercado consumidor. Além disso, estas pesquisas podem fornecer informações para subsidiar os órgãos fiscalizadores no controle do comércio de carvão de origem ilegal. Estas iniciativas podem, portanto, dar apoio à valorização das atividades realizadas pelo pequeno agricultor.

Nesse sentido, este trabalho teve o objetivo de avaliar a qualidade do carvão vegetal da espécie Cecropia glaziovii, produzido em pequenas propriedades rurais, localizadas no município de Biguaçu, estado de Santa Catarina, por meio de análise em laboratório e comparar suas propriedades ao carvão vegetal de outras espécies. 


\section{MATERIAL E MÉTODOS}

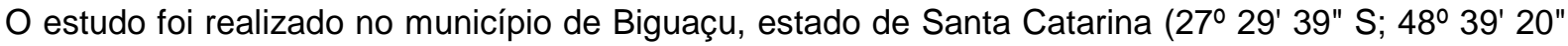
W), em duas propriedades rurais, sendo também o local de coleta das amostras de carvão. Estas propriedades tem o registro nos órgãos ambientais federal e estadual, tanto para a realização do manejo das áreas de cultivo, como o cadastro dos fornos de produção de carvão e autorização de transporte e venda do carvão vegetal. Os agricultores possuem ainda um selo verde, obtido a partir da organização dos agricultores em uma associação que fornece o suporte legal para a obtenção e manutenção deste selo.

O carvão analisado teve três origens: (1) amostras de carvão de Cecropia glaziovii coletadas dos fornos de alvenaria de Biguaçu, SC, após seu resfriamento; (2) amostras de carvão produzido nestes mesmos fornos, porém a partir de várias espécies misturadas e (3) amostras obtidas a partir da carbonização em laboratório da madeira de Cecropia glaziovii coletada nas mesmas propriedades

Para a composição da amostra 1, as amostras de carvão pertencentes a espécie do gênero Cecropia foram identificadas através das características físicas do carvão, visto que as peças conservam o formato da seção do tronco, que normalmente é oco, facilitando a separação dos pedaços de carvão de embaúba. Após a seleção inicial foi avaliada a estrutura anatômica do carvão, com base em comparações com dados de literatura da anatomia da madeira das espécies. Desta forma, foi possível separar com precisão peças de carvão da espécie selecionada para o estudo.

A amostra 1 foi coletada e armazenada em sacos plásticos fechados para evitar alteração das propriedades do carvão, e transportada até o Laboratório de Tecnologia da Madeira do Centro de Ciências Agroveterinárias da Universidade do Estado de Santa Catarina, em Lages. Seis amostras de carvão dos dois produtores foram moídas em moinho de martelo para a determinação das propriedades físicas e energéticas.

A amostra 2 foi coletada da mesma forma que a primeira, no entanto, sem a separação de espécies presentes no carvão, de modo a representar a composição do carvão produzido pelos agricultores.

Para a carbonização em laboratório, amostra 3, foram selecionados três indivíduos da espécie Cecropia glaziovii nas propriedades dos dois agricultores, retirando-se três discos na altura de $1,30 \mathrm{~m}$ das toras para confecção dos corpos de prova. Os discos foram acondicionados separadamente em sacos plásticos devidamente identificados e enviados para o laboratório. Também foi coletado material vegetativo para confecção de exsicatas e posterior identificação e confirmação da espécie estudada.

Após a chegada da madeira no laboratório foi determinado o teor de umidade na base úmida, conforme NBR 14929 (ABNT 2003). O restante do material foi acondicionado em câmara climatizada para estabilização do teor de umidade.

Foram confeccionados sete corpos de prova para cada árvore, com dimensões aproximadas de $2 \times 2$ $x 2,5 \mathrm{~cm}$. Os corpos de provas foram pesados em balança analítica e medidos com auxílio de paquímetro eletrônico antes da carbonização, para a determinação da massa específica aparente e do rendimento gravimétrico e volumétrico do carvão. Três corpos de prova, além dos utilizados para carbonização, foram selecionados para a determinação do teor de umidade antes da carbonização. Posteriormente, os corpos de prova foram envolvidos com papel alumínio, identificados, e colocados em mufla, para carbonização, conforme rampa de aquecimento visualizada na Tabela 1.

Tabela 1. Parâmetros utilizados para carbonização da madeira de Cecropia glaziovii.

Table 1. Parameters used for the carbonization of Cecropia glaziovii wood.

\begin{tabular}{lcc}
\hline Tempo $($ minutos $(\mathrm{h}))$ & Temperatura $\left({ }^{\circ} \mathrm{C}\right)$ & Taxa de aquecimento $\left({ }^{\circ} \mathrm{C} / \mathrm{min}\right)$ \\
\hline 00 & 25 & - \\
$20(0: 00 \mathrm{~h})$ & 150 & 7,50 \\
$87(1: 27 \mathrm{~h})$ & 200 & 2,30 \\
$184(3: 04 \mathrm{~h})$ & 250 & 1,36 \\
$288(4: 48 \mathrm{~h})$ & 350 & 1,22 \\
$362(6: 02 \mathrm{~h})$ & 450 & 1,24 \\
$394(6: 32 \mathrm{~h})$ & 450 & - \\
\hline
\end{tabular}

A carbonização foi realizada a temperatura de $450{ }^{\circ} \mathrm{C}$ para se aproximar ao máximo da temperatura obtida pelos agricultores nos fornos de alvenaria em suas propriedades e que permite uma melhor comparação com as outras amostras.

Foram determinadas para todas as amostras: a porcentagem de voláteis, teor de cinzas e porcentagem de carbono fixo (análise imediata), por meio de Termobalança Gravimétrica (TGA), utilizando- 
se a norma ASTM D 1762 (ASTM 2007), com temperaturas de $900^{\circ} \mathrm{C}$ para a determinação dos voláteis e $700{ }^{\circ} \mathrm{C}$ para cinzas. O poder calorífico superior foi determinado em calorímetro, segundo a norma DIN 51900 (DIN 2000).

Para o carvão de Cecropia glaziovii produzido nos fornos de alvenaria pelos agricultores, foram realizadas dez repetições por haver maior variação nas amostras. Para as amostras carbonizadas em laboratório foram realizadas três repetições de cada indivíduo de Cecropia glaziovii, coletada devido ao maior controle no processo de carbonização. Para as amostras do carvão coletado nas propriedades produzido a partir da mistura de espécies também foram realizadas três repetições.

Também foram obtidos dados de literatura de espécies usualmente utilizadas para a produção de carvão (bracatinga e eucalipto) e uma segunda espécie do gênero Cecropia que também ocorre no sul do Brasil.

Dos resultados obtidos para cada propriedade analisada foram calculados as médias e o desvio padrão. Para cada propriedade analisada foi realizada à análise de variância e as médias dos tratamentos foram comparadas pelo teste de Tukey a $5 \%$ de probabilidade de erro, utilizando programa Sisvar.

\section{RESULTADOS E DISCUSSÃO}

No carvão de Cecropia glaziovii, produzido nos fornos de alvenaria pelos agricultores nas duas propriedades avaliadas (amostra 1), observou-se que o poder calorífico superior variou de 6.380 a 6.754 $\mathrm{Kcal} / \mathrm{Kg}$ (Desvio Padrão (DP) = 104,36); o teor de voláteis de 41,32 a 44,65\% (DP =1,36); o teor de carbono fixo de 50,16 a 53,57\% (DP = 1,293) e o teor de cinzas de 4,92 a 5,78\% (DP =0,24).

O carvão composto por várias espécies, e produzido nos fornos de alvenaria dos agricultores (amostra 2), os valores foram de 7.281 a $7.336 \mathrm{Kcal} / \mathrm{Kg}$ para o poder calorífico, 26,26\%, 2,05 a 2,46\% e $66,02 \%$ para teor de voláteis, teor de carbono fixo e teor de cinzas, respectivamente.

Por outro lado, o carvão de Cecropia glaziovii produzido em laboratório (amostra 3) apresentou valores variando de 6.491 a $6.652 \mathrm{Kcal} / \mathrm{Kg}$ de poder calorífico superior $(\mathrm{DP}=80,80)$; teor de voláteis variando de 32,54 a $36,36 \%$ ( $D P=2,14$ ); teor de carbono fixo de 60,36 a 63,04\% (DP = 1,50) e teor de cinzas de 3,08 a $4,42 \%(D P=0,68)$.

A comparação entre os valores médios de cada amostra analisada pode ser visualizada na Tabela 2.

Tabela 2. Comparação entre as propriedades energéticas do carvão vegetal das amostras analisadas Table 2. Comparison between the energetic properties of the charcoal of the analyzed samples.

\begin{tabular}{lllll}
\hline Carvão Vegetal & PCS (Kcal/Kg) & TV (\%) & TC (\%) & CF (\%) \\
\hline Amostra 1 & $6.480 \mathrm{~b}$ & $43,19 \mathrm{a}$ & $5,20 \mathrm{a}$ & $51,61 \mathrm{c}$ \\
Amostra 2 & $7.300 \mathrm{a}$ & $26,26 \mathrm{c}$ & $2,26 \mathrm{~b}$ & $66,02 \mathrm{a}$ \\
Amostra 3 & $6.573 \mathrm{~b}$ & $35,00 \mathrm{~b}$ & $3,68 \mathrm{~b}$ & $61,32 \mathrm{~b}$ \\
\hline
\end{tabular}

Nota 1: Médias seguidas da mesma letra não apresentam variação estatística significativa para o Teste de Tukey $(p>0,05)$.

Nota 2: Amostra 1 = carvão de Cecropia glaziovii dos fornos de alvenaria; Amostra 2 = carvão contendo várias espécies produzida nos fornos de alvenaria; Amostra 3 = carvão obtido da carbonização em laboratório da madeira de Cecropia glaziovii. $\mathrm{PCS}=$ Poder calorífico superior; TV = teor de voláteis; $\mathrm{TC}=$ teor de cinzas; $\mathrm{CF}=$ teor de carbono fixo.

Houve variação na qualidade energética do carvão para todas as propriedades, tanto em função da espécie componente (cecrópia e mistura de espécies), quanto em função da forma de carbonização (carvão oriundo dos fornos e carvão produzido em laboratório).

A variação derivada da forma de carbonização é devida da heterogeneidade do processo produtivo do carvão vegetal nos fornos de alvenaria. Nestes, não se tem um controle efetivo da carbonização das madeiras. O controle do processo é empírico e não busca uma melhor qualidade do carvão vegetal e sim um volume maior como resultado, já que a comercialização é feita baseada no volume de carvão que é produzido.

Apesar destes fornos terem um custo baixo, de fácil construção, facilidade no momento da vedação de entrada de ar e ter facilidade no controle da carbonização, PIMENTA \& BARCELLOS (2000) descrevem algumas desvantagens dos mesmos: o rendimento gravimétrico do carvão é baixo promovendo uma má utilização da matéria prima, as paredes perdem muito calor aumentando o tempo de carbonização, o carvão produzido tem qualidade bastante variável conforme a posição das peças no forno, não existe parâmetros de qualidade do carvão para a indústria consumidora, etc.

Portanto, o carvão de cecrópia produzido em laboratório teve melhor qualidade que o carvão da mesma espécie coletado nos fornos, pois teve menores teores de voláteis e de cinzas e maior teor de 
carbono.

A melhor qualidade da amostra 3 comparada a amostra 1, se deu devido ao controle efetivo da carbonização em laboratório principalmente em relação a temperatura e ao tempo de carbonização; este controle é feito pela rampa de aquecimento (Tabela 1), que permite minimizar ao máximo as variações de temperatura. A carbonização em laboratório permite uma uniformidade do carvão vegetal produzido, pois os tamanhos dos corpos de prova são semelhantes entre si e a mesma posição que todos os corpos de prova ficam na mufla também promovem essa uniformidade no material carbonizado, não ocorrendo a presença de tições.

O carvão vegetal obtido da mistura de diferentes espécies apresentou melhor qualidade energética em comparação com o carvão de crecópia para todas as propriedades, tendo maior poder calorífico, menores teores de voláteis e cinzas e maior teor de carbono fixo.

Entre carbono fixo e teor de materiais voláteis e de cinzas no carvão existe uma relação; a associação entre os teores de voláteis e de cinza no carvão vegetal origina maiores teores de carbono fixo e vice-versa.

A mistura das espécies (amostra 2) favorece a melhoria da qualidade do carvão em função da existência de madeiras com diferentes massas específicas e composição química imediata.

A produção de carvão vegetal na região de estudo é destinada exclusivamente ao uso doméstico (churrasco); os agricultores indicam a boa qualidade do produto no mercado para seu fim, porém segundo RIBEIRO \& VALE (2006) o carvão vegetal para ser considerado de boa qualidade para o uso doméstico deve reunir algumas características como: alta densidade relativa aparente; alto teor de carbono fixo; alto poder calorífico; baixa umidade; baixo teor de materiais voláteis e baixo teor de cinzas.

No Brasil, apenas o estado de São Paulo criou uma legislação que regula a qualidade que o carvão vegetal deve ter para uso doméstico, estabelecendo os parâmetros mínimos ou máximos para as propriedades de umidade, teor volátil, carbono fixo e teor de cinzas do carvão. Portanto, em estudos científicos que vêm estudando a qualidade do carvão vegetal para uso doméstico, essa legislação foi utilizada para determinar a qualidade desse produto (BRAND et al. 2015).

Assim, considerando como parâmetro de comparação os valores estabelecidos pelo Selo Premium, promulgado pela Resolução no 40 SAA/2015, da Secretaria de Agricultura e Abastecimento do Estado de São Paulo, alterando a Resolução SAA o 10, de 11 de julho de 2003 (SÃO PAULO 2015), que determina que o teor de carbono fixo deve ser superior a $73 \%$ e o teor de cinzas deve ser inferior a $1,5 \%$, nenhuma das amostras analisadas tem qualidade para o uso doméstico.

$\mathrm{Na}$ Tabela 3 é apresentada a comparação da qualidade do carvão de espécies de Cecropia com outras espécies florestais e os valores de massa específica básica destas espécies.

Tabela 3. Massa específica básica da madeira e propriedades energéticas do carvão vegetal de diferentes espécies madeireiras.

Table 3. Basic density and energetic properties of charcoal from different wood species.

\begin{tabular}{lccccc}
\hline \multicolumn{1}{c}{ Espécie } & MEB $\left(\mathrm{g} / \mathrm{cm}^{3}\right)$ & PCS $(\mathrm{Kcal} / \mathrm{Kg})$ & TV $(\%)$ & TC $(\%)$ & CF $(\%)$ \\
\hline Mimosa scabrella & 0,58 & $6.988^{1}$ & $30,39^{1}$ & $1,64^{1}$ & $68,05^{1}$ \\
Eucalyptus bentamii $^{b}$ & 0,49 & $8.777^{2}$ & $17,17^{2}$ & $0,96^{2}$ & $81,85^{2}$ \\
Eucalyptus grandis $^{c}$ & 0,50 & $7.632^{3}$ & $20-25$ & 1,70 & $75-80$ \\
Cecropia glaziovii & 0,22 & 6.573 & 35,00 & 3,68 & 61,32 \\
\hline
\end{tabular}

Fonte: ${ }^{1}$ FRIEDERICHS et al. (2015), ${ }^{2}$ LIMA et al. (2011), ${ }^{3}$ OLIVEIRA et al. (2012). ${ }^{\mathrm{b}} \mathrm{BROGNI}$ et al. (2004), ${ }^{\circ}$ VALENTE et al. (1985). Nota: MEB = massa específica básica; PCS = Poder calorífico superior; TV = teor de voláteis; TC = teor de cinzas; $\mathrm{CF}=$ teor de carbono fixo.

As médias do carvão de Cecropia, encontradas para poder calorífico superior e porcentagem de carbono fixo foram inferiores quando comparadas a outras espécies de importância econômica, utilizadas para a produção de carvão vegetal, como a Mimosa scabrella, Eucalyptus bentamii e Eucalyptus grandis. As médias de porcentagem de voláteis e teor de cinzas foram superiores aos das outras espécies.

A Cecropia glaziovii é considerada uma madeira mole pelos agricultores do município de Biguaçu, isto é comprovado por sua massa específica básica (MEB $-0,22 \mathrm{~g} / \mathrm{cm}^{3}$ ) que foi determinada neste trabalho. Segundo o FOREST PRODUCTS LABORATORY (1974), esta madeira pode ser classificada pela sua densidade como excessivamente leve. A densidade da madeira é um parâmetro de grande importância a ser analisado dentro das várias propriedades físicas da madeira. Ela influencia significativamente as outras propriedades bem como a qualidade dos seus produtos (BRASIL \& FERREIRA 1971). 
A Cecropia glaziovii, juntamente com outras espécies componentes do carvão vegetal produzido na agricultura familiar são consideradas pelos agricultores como matéria-prima de baixa qualidade para a produção de carvão, quando comparadas com espécies de Eucalyptus e Mimosa scabrella (Bracatinga). No entanto, continuam a utilizá-las em função de sua disponibilidade nas áreas exploradas. Os resultados obtidos neste trabalho corroboram este conhecimento empírico adquirido pelos agricultores ao longo de suas experiências com a carbonização de diferentes espécies madeireiras.

\section{CONCLUSÃO}

A forma de carbonização influencia a qualidade do carvão vegetal produzido com Cecropia glaziovii.

O carvão vegetal produzido com a mistura de diferentes espécies, nos fornos de alvenaria, possui melhor qualidade comparada ao carvão contendo somente Cecropia glaziovii.

O carvão produzido nos fornos de alvenaria contendo somente a espécie Cecropia glaziovii foi o de menor qualidade energética.

A qualidade do carvão da espécie Cecropia glaziovii é inferior a qualidade do carvão obtido de outras espécies, tradicionalmente utilizadas para a produção de carvão vegetal, como do gênero Eucalyptus e Mimosa.

Apesar da qualidade inferior, a abundância destas espécies na formação florestal presente na região de estudo, justifica a continuidade de seu uso para produção de carvão vegetal.

Estudos futuros devem definir a proporção de uso desta espécie na mistura de espécies para produção de carvão, de forma que sua qualidade inferior não interfira na qualidade geral do carvão produzido na região de estudo.

\section{REFERÊNCIAS}

ASTM. 2007. American Society for Testing and Material. ASTM D 1762 - 84: Standard Test Method for Chemical Analysis of Wood Charcoal. West Conshohocken: ASTM International. 2p.

ABNT. 2003. Associação Brasileira de Normas Técnicas. NBR 14929: Madeira - Determinação do teor de umidade de cavacos - Método por secagem em estufa. Rio de Janeiro: ABNT. 3p.

BRAND MA et al. 2013. Análise da qualidade da madeira e do carvão vegetal produzido a partir da espécie Miconia cinnamomifolia (De Candolle) Naudin (Jacatirão-açu) na agricultura familiar, em Biguaçu, Santa Catarina. Scientia Forestalis 41: 401-410.

BRAND MA et al. 2015. Quality of charcoal for domestic consumption marketed in the Southern Highlands Region of Santa Catarina. Árvore 39: 1165-1173.

BRASIL MAA \& FERREIRA M. 1971. Variação da densidade básica da madeira de Eucalyptus alba Reinw, E. saligna Smith e E. grandis, Hill ex-Maiden aos cinco anos de idade, função do local e do espaçamento. Instituto de Pesquisas e Estudos Florestais 2: 129-149.

BROGNI E et al. 2004. Massa específica, contração, rigidez e resistência a flexão estática da madeira de Eucalyptus benthamii, Acacia mangium, Liquidambar styraciflua e Spathodea campanulata. In: 1 Congresso Brasileiro de Industrialização da Madeira e Produtos de Base Florestal. Resumos... Pinhais: FAPESP.

DIN. 2000. Deutsches Institut Für Normung. DIN 51900: Determining the gross calorific value of solid and liquid fuels using the bomb calorimeter, and calculation of net calorific value. Berlim: Standards Library.

FOREST PRODUCTS LABORATORY. 1974. Wood handbook: Wood as an engineering material. Washington: Superintendent of Documents U.S. Government Printing Office. 521p. (Agriculture Handbook 72).

FRIEDERICHS G et al. 2015. Qualidade da madeira e do carvão vegetal de bracatinga (Mimosa scabrella Benth.). Revista Ciência da Madeira 6: 78-87.

IBGE. 2019. IBGE Censo Agropecuário 2016. Resultados preliminares 2017. Disponível em: <https://sidra.ibge.gov.br/tabela/6763\#resultado>. Acesso em: 06 mai. 2019.

INCRA. 2019. Classificação dos imóveis rurais. Disponível em: <http://www.incra.gov.br/tamanho-propriedades-rurais>. Acesso em: 06 mai. 2019.

LIMA EA et al. 2011. Caracterização Dendroenergética de árvores de Eucalyptus bentamii. Pesquisa Florestal Brasileira 31: 9-17.

LINDEMANN RH. 2010. Ensino de química em escolas do campo com proposta agroecológica: contribuições a partir da perspectiva freireana de educação. Tese (Doutorado em Educação Científica e Tecnológica). Florianópolis: UFSC. 339p.

LINGNER DV et al. 2013. Grupos florísticos estruturais da Floresta Ombrófila Densa em Santa Catarina. In: VIBRANS AC et al. (Eds.). Inventário Florístico Florestal de Santa Catarina. Vol. IV. Floresta Ombrófila Densa. Blumenau. Edifurb. p. 143-157.

LORENZI H. 2002. Árvores brasileiras: manual de identificação e cultivo de plantas arbóreas nativas do Brasil. 2.ed. Nova Odessa: Plantarum. 368p.

OLIVEIRA AC et al. 2012. Avaliação de diferentes níveis de desbastes nas propriedades da madeira e do carvão vegetal de Eucalyptus grandis x Eucalyptus urophylla. Floresta 42: 59-68. 
PIMENTA AS \& BARCELLOS DC. 2000. Como produzir carvão para churrasco. Viçosa: CPT. 76p.

RIBEIRO PG \& VALE AT. 2006. Qualidade do carvão vegetal de resíduos de serraria para o uso doméstico. In: Reunião Anual da Sociedade Brasileira para o Progresso da Ciência. Resumos... Belém: SBPC. 1p.

SÃO PAULO. 2015. Secretaria de Agricultura e Abastecimento de São Paulo. Resolução n40 SAA, de 14 de dezembro de 2015. 11p.

SIMINSKI A \& FANTINI AC. 2007. Roça-de-toco: uso de recursos florestais e dinâmica da paisagem rural no litoral de Santa Catarina. Ciência Rural 37: 1-10.

STEENBOCK W. 2009. Domesticação de bracatingais: perspectivas de inclusão social e conservação ambiental. Tese (Doutorado em Recursos Genéticos Vegetais). Florianópolis: UFSC. 262p.

ULLER-GÓMEZ C \& GARTNER C. 2008. Um caminho para conhecer e transformar nossa comunidade. Relatório final de pesquisa vinculada ao TOR 23/2006. Florianópolis: EPAGRI. 111p.

VALENTE OF et al. 1985. Efeito da temperatura de carbonização nos rendimentos e propriedades do carvão vegetal produzido. Árvore 9: 28-39. 